\title{
Food and Nutrition Justice: How to Make it More Newsworthy?
}

\author{
Paranjoy Guha Thakurta and Subi Chaturvedi
}

\begin{abstract}
Growing corporatisation and commercialisation of the mass media in India and the world have resulted in facts and issues relating to food and nutrition justice being pushed to the fringes. In an environment where news-gathering and gatekeeping processes result in a continuous tussle for prominence and stories have to be delivered under short deadlines, articles are measured against values such as currency, immediacy and impact on specific population segments. If complex and nuanced issues and facts on food and nutrition are to be highlighted, it would require consistent efforts on the part of advocacy groups to inform and sensitise media practitioners. This article explores how stories on food security and nutrition justice can be made more newsworthy and how opportunities can be optimised to bring greater prominence to reports and analytical articles on these subjects. It also elaborates on conflicts and discourses within the Indian media and civil society by critically examining reportage on these issues, and suggests ways in which to engage with the media.
\end{abstract}

\section{Introduction}

Facts and issues relating to food and nutrition justice find expression in the mass media across the world and in India in ways that range from the sensational to the mundane. The mass media are not homogeneous and the manner in which facts and issues relating to food and nutrition justice are highlighted or ignored depends on the character, ideology and position of a particular publication, radio station, television channel or website.

For sections of the corporate media where commercial motives of profit maximisation are predominant, news about hunger and the absence of nutrition justice that affect the underprivileged are rarely emphasised, except on occasions when facts and issues are too stark and important to be ignored (for the specific media organisation's readers, listeners or viewers) and, on such occasions, the news stories tend to be hyped to attract maximum attention. These sections of the media are usually heavily dependent on advertising revenue and for such media organisations, the poor and the hungry are often not important enough as potential consumers for advertisers. In other sections of the media that are relatively more concerned about food and nutrition issues for political, ideological and other reasons, news stories and analytical articles on such subjects can sometimes be presented in a dull, prosaic and unattractive manner, thereby reaching out to those who are already interested in such subjects or merely 'preaching to the converted'.

Since the mass media have been and remain influential in shaping public opinion, especially in democracies, it has become increasingly important for policymakers, social activists and all those concerned about food and nutrition justice to devise methods and strategies to use the media to reach out to different sections. Whereas these methods and strategies would necessarily have to be flexible and specific to situations, it is imperative to understand why, when, how and under what circumstances certain facts and issues become newsworthy (or not) and for which sections of the media. It is, therefore, crucial to understand what motivates editors, publishers, journalists, photographers, broadcasters and other media professionals to highlight particular sets of facts and issues and why they act and work in the way they do.

As a purely scientific issue, food and nutrition justice can come across as a bit too complicated for the lay public, the proverbial person on the 
street. As an economic and social problem, it can be ignored because of its silent nature. As a political subject, it comes to the fore only when a major disaster takes place, such as a drought or famine. Advocacy programmes need to retrieve information and analysis from closed-door conferences and make them public and accessible to large sections through the media by, among other things, addressing people in a language and style that is easily comprehended and therefore, appreciated. Further, instead of following a blanket approach in presenting the case for food and nutrition justice to all sections of the mass media, advocates and experts must adopt a nuanced approach in articulating messages that are designed for specific audiences.

At the same time, those articulating facts and messages need to be aware of the manner in which media organisations work, the short deadlines under which journalists often have to operate, how news-gathering is a 24/7 exercise, and the corporate and political pressures that are exerted on media organisations. Only by acquiring a deep understanding of the manner in which media organisations work and the compulsions that operate on them can the services of media practitioners be effectively utilised to bridge the divide between those who know and those who don't. Facts, messages and propositions may have to be segmented for target audiences and designed for particular media platforms and media genres for these to be deemed more newsworthy.

Obtaining better and more extensive media coverage for food and nutrition-related issues is easier said than done, given the unpredictable and unexpected nature of information flows. For example, news about an important survey on nutrition justice may get underplayed on a day when there is a major accident or natural disaster. The London-based worldwide charity, Save the Children, released a report in early 2012, entitled A Life Free from Hunger: Tackling Child Malnutrition, containing the following statistics that many may consider 'significant' and even 'startling'. Every hour of every day, 300 children are dying on account of malnutrition, the underlying cause of more than a third of the deaths of 2.6 million every year. Malnutrition takes more lives than a disease like malaria in developing nations but is not recorded on death certificates and, as a result, remains ineffectively addressed. Even for children who survive, long-term malnutrition causes devastating and irreversible damage: at least 170 million children are affected by stunting. This means that not only are they too short for their age - they are also likely to enrol at school later and to do less well academically. Iodine deficiency, a type of malnutrition caused by a lack of specific nutrients, affects one-third of schoolchildren in developing countries. Childhood malnutrition lessens productivity - stunted children are predicted to earn an average of 20 per cent less when they become adults. If current trends continue, the lives of more than 450 million children globally will be affected by stunting in the next 15 years.

Did the data contained in this report get widespread media coverage? The answer is that the coverage was probably not as great as those behind the report may have wanted or hoped for. Why? One reason, as the report itself has pointed out, was that a number of significant political developments took place during 2011 including the Arab Spring, the killing of Osama bin Laden and Muammar Gaddafi, the sovereign debt crisis in Europe - which diverted public attention from the 'hunger and malnutrition crisis affecting millions of children [that] has gone unchecked' (Save the Children 2012).

Another reason could be that the reports relating to hunger and nutrition justice needed more 'humanising'. Faces of people had to be presented before cold statistics. Individual cases help create 'human interest' news stories which, in turn, can help mobilise public opinion around these stories. For example, it could be stated that 'Girish is three, lives in a slum in Mumbai and weighs only 50 per cent of that of the normal weight of a boy his age' to start a news story instead of statistics of the sort quoted. The readers of a newspaper or the viewers of a television programme may sympathise (or even empathise) with Girish almost instantaneously, but may not relate to a chart tabulating statistics on nutritional indicators relating to a large group of nameless three-year-old children.

As news flows take place round the clock and since news-gathering efforts often entail very short deadlines, special efforts need to be made to highlight the 'right' facts for the 'right' people and get designated advocates to get the messages 'right'. The Berkeley Media Studies 


\begin{tabular}{ll}
\hline Table 1 Speaker types & \\
\hline Speaker types & $\%$ \\
\hline Advocate & 39 \\
Government agency representative & 30 \\
Nutritionist/registered dietitian & 23 \\
Researcher/professor & 19 \\
Parent & 17 \\
Student, child or youth & 13 \\
Businessperson & 13 \\
Physician & 13 \\
Teacher & 6 \\
School administrator & 6 \\
Other & 3 \\
\hline
\end{tabular}

Group analysed a representative sample of newspaper coverage of policy debates around childhood nutrition to determine the dominant subjects, arguments, spokespeople, statistics and metaphors being used on the issue between 1998 and 2000, and published its findings in 2001. The study revealed that media coverage on the issue was barely local and that most stories were picked up from news agencies/wire services. The group suggested that advocates had work to do on pitching stories to local reporters by connecting national issues to what was taking place at a local level.

Importantly, the Berkeley Media Studies Group said it was critical to pay attention to who was being quoted in news stories on nutrition and food justice issues. The particular person identified is one who is turned to by reporters as an expert or a reliable source, an individual who has the credentials and the credibility to influence if not dominate the discourse and debate on the subject. Table 1 provides the findings related to the type of person who was quoted in the stories sampled.

Of interest here is the importance given in news stories to advocates, or those who by definition take a position on various food policies and health issues, including nutritionists, researchers and other public health professionals.

The UNESCO media handbook published in 2011 talks about how a boy who eats a plate of rice but little else may not be getting all the nutrients that his growing body needs. In order to create a holistic story around the issue, the journalist would have to be assisted and guided to investigate, understand and highlight the fact that there are also 'important differences in the duration and severity of the way in which people experience food insecurity' (UNESCO 2011).

Here is an example of how a report was 'localised' for coverage in Indian media. On 11 October 2010, the Press Trust of India (PTI), the country's largest news agency, put out the following report based on a study conducted by the International Food Policy Research Institute (IFPRI).

New Delhi: India has been ranked 67, way below neighbouring countries like China and Pakistan, in a new Global Hunger Index by IFPRI.

The index, released on Monday, rated 84 countries on the basis of three leading indicators - prevalence of child malnutrition, rate of child mortality, and the proportion of people who are calorie deficient.

China is rated much ahead of India at ninth place, while Pakistan is at the 52nd place on the 2010 Global Hunger Index, released by IFPRI in association with German groups, Concern Worldwide and Welthungerhilfe.

In India, the high index scores are driven by high levels of child underweight resulting from the low nutritional and social status of women in the country, the report pointed out, adding that India alone accounts for a large share of the world's undernourished children.

India is home to 42 per cent of the world's underweight children, while Pakistan has just 5 per cent, it added.

This report put out by the PTI was used by various newspapers, websites and television channels because the first sentence of the story made it suitable for a headline of the sort the agency itself gave: 'India ranks below China, Pakistan in global hunger index'. The story was carried because the agency reporter was astute to make a comparison between India, its bigger neighbour China and its smaller and supposedly 'less developed' neighbour Pakistan. 
What can be done to enhance the quantity and quality of coverage in the mass media on facts and issues related to hunger and nutrition justice? A few suggestions follow.

The information should be clearly segmented into 'hard' news and 'soft' feature stories. The latter category would include 'background briefs' that could assist writers of editorial articles and opinion columns and commentators and analysts who appear on television channels and radio programmes. There are different space allocations for these categories of stories in the print and electronic media. While disseminating the findings of a survey, research or a poll, the interest groups concerned should be ready with multiple versions of the story written for different audiences and different kinds of media professionals.

Journalists specialised in writing/reporting/ analysing on particular 'beats' or areas of experience need to be targeted differently. For example, a journalist focused on science and technology may require additional (more detailed) inputs in comparison to a 'generalist' journalist. This is also true of those representing specialised journals or television channels or websites.

A few points need reiteration. It is important to have 'people' in stories over and above statistics. Journalists could be guided to people and places who could serve as 'examples' or 'case studies' that could provide 'human interest' to stories. Such people (or places) may help illustrate a story and would be of particular interest to a photographer or videographer. Moreover, personal interviews with experts, thought-leaders and opinion-makers increase the chances of wider media coverage. Celebrity endorsements of issues also help, although many advocates may argue that such forms of garnering publicity may trivialise issues and messages. The contrary point of view is that if a well-known individual (actor, political leader or corporate captain) gets convinced about the need to disseminate a particular message and endorses it, the cause itself becomes bigger than the person endorsing the cause. (One instance is the popular Indian actor Amitabh Bachchan promoting the government of India's pulse polio programme.)

All parameters and news values which apply to any news story will also apply to stories on food
Figure 1 Inverted pyramid news writing style

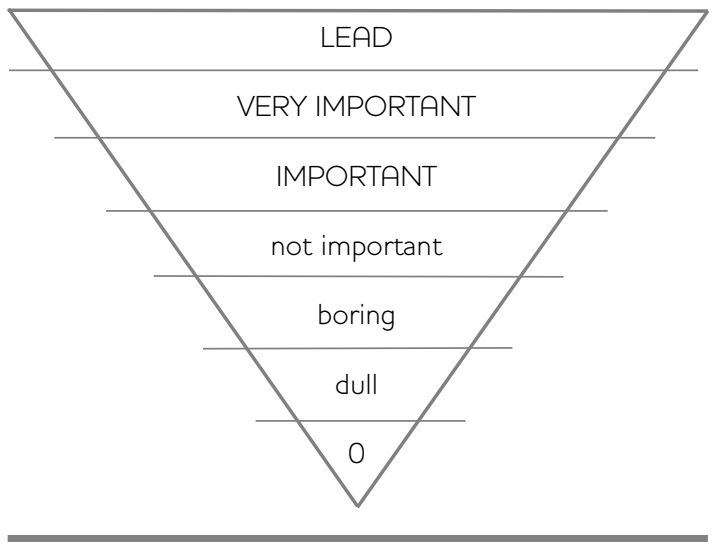

and nutrition justice. Determine the five 'W's and an ' $\mathrm{H}$ ' that are important in any and every news story: who, what, when, where and why and how. Individuals interviewed should be trustworthy and should have a point of view. The lead (also spelt lede) or the first one or two sentences, should summarise the most important points in the story, grab the attention of the reader/listener/viewer and ensure that she/he stays till the end. This is often described as the 'inverted pyramid' style or structure or a method used in journalistic writing where the broadest and most important information comes right on top of the story with the less important and more narrow facts following.

Soon after the lead should come the 'nut graph' or 'nut graf' (a compression of the phrase 'nutshell paragraph') that explains the news value of the story. Unlike news stories, feature articles could begin differently and follow a narrative style (as in works of fiction). It is worth remembering that in most news stories, the paragraphs are short, rarely exceeding more than a few sentences.

News values, occasionally referred to as news 'criteria' or news 'factors' are a conceptual framework used within journalism studies and journalism education to describe gatekeeping practices of the mainstream news media. Specifically, news values are defined as qualities of events that increase the likelihood of their being covered in the news.

Newsworthiness can be described in numerous ways with different determinants defining the term. The way in which editors perceive readers' 
interests is a very important factor in the gatekeeping process. News determinants are yardsticks by which an editor determines what portion of the day's news he/she will use. Numerous lists of news values exist and have been generated using a wide variety of methods, including interviews and surveys of journalists, case studies of news coverage, newsroom ethnographies, content analyses of finished news items, and plain simple introspection by journalists-cum-academics. Most journalism curricula agree on five main news determinants: timeliness, prominence (importance), proximity (locality), consequence, and human interest. These are, of course, not the only criteria that determine what is carried and what is not; in other words, editorial subjectivity often can and does influence what is reported, what is ignored, what is highlighted and what is not emphasised.

Bizarreness and oddity also attract the attention of journalists. The story of an entire community, including children, subsisting for days on end eating mud in a village in Uttar Pradesh in India made a major news story in April 2010, ${ }^{1}$ causing a huge public outcry and forcing the State Government to take quick remedial measures.

Of particular value are stories brought to the public ahead of the competition. These become 'scoops' or 'exclusive' news breaks. All journalists want 'exclusive' stories and one way to obtain relatively greater coverage in a particular media outlet, is to provide a specific journalist 'advance' information before facts are released to everybody. This strategy can, however, fail if journalists from competing media outlets feel that they have been deliberately deprived of information that has been provided to a particular journalist as some sort of 'favour'.

The examples and comments that follow, by and large, reflect the failure of large sections of the mainstream media in India to make food and nutrition issues sufficiently newsworthy. These sections of the media are usually heavily dependent on advertising revenue and, for such media organisations, the poor and the hungry are often not important enough as potential customers for advertisers. It could be argued by some that reporting on the poor and the hungry is not the best way to attract the kind of readers that are targets for advertisers. The contrary argument would be that not all those who are reasonably well-off - and hence, form part of the target audience of advertisers - are so insensitive and/or insulated from the plight of the poor and the hungry that they do not want to read/hear/ view news reports on hunger and poverty. There is more than an element of conviction in both sides of the argument.

Speaking on hunger in India at a public meeting on the right to food at New Delhi on 10 January 2003, Nobel Laureate Amartya Sen observed:

When India achieved Independence, more than 50 years ago, the people of the country were much afflicted by endemic hunger. They still are. Since India is often considered to be one of the great success stories in tackling the food problem, the belief in success has to be scrutinised in the light of the grim reality that we can observe (Sen 2003).

One reason for Sen's observations in this regard is that sections of the media have, of late, tended to highlight 'positive' or 'feel good' news stories instead of 'negative' stories on the continuance of widespread hunger and malnutrition in the country.

Sen's collaborator Jean Drèze has remarked that the 'most startling aspect of the nutrition situation in India is that it is not much of an issue in public debates and electoral politics'. He reviewed the editorial page of The Hindu newspaper

over a period of six months (January to June 2000)... [and] found that health, nutrition, education, poverty, gender, human rights and related social issues combined accounted for barely 30 out of 300 (opinion) articles. Among these 300 articles, not one dealt with health or nutrition (Drèze 2003).

Yet, ironically, The Hindu is one of India's most respected news dailies and perhaps the only one with a dedicated rural affairs editor, P. Sainath, who has written extensively on farmers' suicides.

Prominent Indian agricultural scientist and Member of Parliament, M.S. Swaminathan, has often remarked that while starvation deaths may make news, gnawing hunger does not. Even in instances where starvation deaths are alleged, local authorities tend to dismiss these stories as 
'sensational' and attribute the deaths to disease. Sainath points out

that the emphasis on 'starvation deaths' to the exclusion of all else is damaging. Widespread hunger is a much larger issue... An exclusive focus on 'starvation deaths' - disconnected from the larger canvas - seems to imply this: if they don't die, everything's all right.

A media scholar and independent journalist based in Bangalore, Ammu Joseph, scrutinised six English dailies published from Bangalore (four of them national) over the ten days leading up to 26 January 2006 (India's Republic Day). She highlighted a few examples of stories on hunger. On 24 January, the Asian Age carried a story about a woman who had killed herself and her four-year-old son in Muzaffarpur district, Bihar, after fighting starvation for several months. On 21 January, Vijay Times published a report on a so-called 'kidney sale centre' set up by desperate farmers in Maharashtra to draw attention to their inability to feed their families on account of crop failure and debt. On 17 January, an Op-Ed (opposite the editorial) page article in the Deccan Herald headlined 'Making education more important than a meal' referred in passing to the fact that a midday meals programme introduced after a Supreme Court directive was the single most important reason for the significant decline in the dropout rate among schoolchildren in the state of Karnataka. On 21 January, economist L.C. Jain wrote an article in the Asian Age which discussed the importance of a grain bank set up by a gram panchayat (village council) in Gadag district, Karnataka, to ensure that no one in the village went hungry.

According to Joseph, the most common references to food in the Bangalore publications scrutinised by her were in restaurant reviews and promotions, reports on food festivals and events such as a lunch at a five-star hotel to promote vegetarianism, news about the launch of a book on cooking, advice on diet and nutrition (with headlines such as 'Amla [a kind of sour gooseberry] works wonders on your health', 'Healthy diet for healthy hair'), research findings relating to food and health ('Chocolates good for heart', 'Wine and cheese not best match'), consumer information (on the results of tests on brands of potato chips and banana chips) besides, of course, recipes (often sourced from chefs in expensive hotels and restaurants).

It is not as if the media in India has completely failed in highlighting facts and issues relating to hunger and nutrition justice. Three districts in the eastern Indian state of Orissa - Kalahandi, Koraput and Bolangir - became household names largely due to the extensive coverage given in the media to droughts and deprivation in these areas. According to an article in the Hindustan Times published on 16 January 2003, hunger deaths first rocked politics in Orissa in 1965-66 when drought in Kalahandi and Koraput led to a famine that claimed around 1,000 lives. In 1985-86, in the Kashipur region in Koraput district, 200 people died on account of starvation. In 1988-89, another 300 people died in the state. The Orissa government refused to acknowledge that hunger was the cause of the deaths. In 2002, Orissa again witnessed around 345 starvation deaths. The State Government attributed these deaths to disease and snakebites. The point being made here is the reluctance of local authorities to acknowledge starvation deaths and to attribute such deaths to other factors.

According to Jean Drèze, who has played an important role in the right to food campaign in India, 'media coverage of hunger and related issues has considerably increased during the last couple of years'. He has added,

there is a useful shift of attention from starvation deaths to chronic hunger, which is absolutely essential if the problem of endemic undernutrition in India is to be tackled with adequate resolve. I am not suggesting that this surge of media interest in hunger-related issues is due to the right to food campaign alone, but I do think that the campaign has contributed to it. In all media outfits, there are committed and open-minded journalists who respond positively when they are presented with engaging material on social issues (Drèze 2003).

With the growing use of the internet and the rise of citizen journalism on television channels, the boundaries surrounding journalism have widened and not narrowed. Despite the existence of a sharp 'digital divide' - barely 10 per cent of India's population had used the internet before the end of 2011 - the internet 
has enabled and is expected to continue to enable ordinary citizens to express with greater ease their views on a host of issues, including issues relating to food and nutrition, thereby contributing to greater plurality in the media. The differences between 'traditional' and 'professional' journalists and 'ordinary' citizens have become fuzzy and the lines demarcating genres of journalism have got blurred. This phenomenon is certain to grow and will pose new challenges for advocates and civil society activists engaged in issues relating to food and nutrition security. Advocacy groups will need to include and address their campaigns to users of new media, and actively use the web, including social networking sites such as Twitter and Facebook, to disseminate information and messages.

\section{Note}

1 See www.hindustantimes.com/News-Feed/ India/Not-enough-food-so-children-learn-to-

\section{Bibliography}

Allern, S. (2002) 'Journalistic and Commercial News Values: News Organizations as Patrons of an Institution and Market Actors', Nordicom Review 23.1-2: 137-52

Drèze, Jean (2003) Food Security: Beating Around the Bush, www.righttofoodindia.org/data/ jeanhumanscape.pdf (accessed 25 April, 2012)

Eilders, C. (2006) 'News Factors and News Decisions: Theoretical and Methodological Advances in Germany', Communications 31.1: $5-24$

Golding, P. and Elliott, P. (1999) 'Making the News', in H. Tumber (ed.), News: A Reader, New York: Oxford University Press
Sen believes that in India's democratic system, 'nothing is as important as clear-headed public discussions of the causes of deprivation and the possibility of successful public intervention' (Sen 2003). Sainath contends that 'if the media do their job, the public will respond'.

Yet public-spirited intellectuals, advocates and journalists like Sen, Drèze and Sainath would probably still acknowledge that for much of India's corporate media, the wardrobe malfunction of a model on a ramp will be considered more newsworthy than a story on a farmer committing suicide or on the absence of nutrition justice.

eat-mud/Article 1-527187.aspx and http://news.bbc.co.uk/2/hi/8682558.stm.

Harcup, T. and O'Neill, D. (2001) 'What is News? Galtung and Ruge Revisited', Journalism Studies 2.2: 261-80

Save the Children (2012) A Life Free from Hunger: Tackling Child Malnutrition, London: Save the Children

Sen, A. (2003) These Food Subsidies Inflate Prices, www.indiatogether.org/2003/oct/ecofoodprice.htm, (accessed 25 April 2012)

UNESCO (2011) Food Security and Nutrition: A Guide for Journalists, www.foodsecurity.gov.kh/ sites/default/files/documents/Media_ Handbook_Layout_Final_Email.pdf (accessed 25 April 2012) 